\title{
Determinants of contraceptive use among married women in Tanzania: Policy implication
}

\author{
Mackfallen G. Anasel ${ }^{1 *}$ \& Upendo J. Mlinga ${ }^{2}$ \\ ${ }^{1}$ School of Public Administration and Management, Mzumbe University, Morogoro, Tanzania \\ ${ }^{2}$ Tanzania National Roads Agency (Regional Manager's Office-Morogoro)
}

\begin{abstract}
Family planning as an ability for couples to control the timing and number of their pregnancies play a crucial role in reducing fertility rate when it efficient and effectively implemented. Despite $96.5 \%$ having knowledge on family planning, only $20 \%$ are using modern methods. The main objective of study was to find out the determinants of contraceptive use among married women and policy implication in Tanzania. The study use Tanzania Demographic and Health Survey 2004-2005. Data were analysed quantitatively through, binary and multinomial logistic regression. Results show that husband disapproval of contraceptive use, women education, husband and women approval of family planning, discussion of family planning with partners, wealth index, and religion, are determinants of contraceptive use. Based on these results, we recommend increasing women enrolment in all levels of education. This paper suggests that having nice policy, on women empowerment is important but its effective implementation is the most important.
\end{abstract}

Keywords: Family planning; Determinants; Policy implication; binary and multinomial logistic regression

\section{Résumé}

Le planning familial comme un moyen pour les couples de calculé et contrôle le nombre de leurs grossesses, jouer un rôle très important en réduite le taux de fécondité si il est exécuter efficacement. Malgré le fait que, $96.5 \%$ ont une bonne connaissance du planning familial, $20 \%$ seul mettre en place les méthodes modernes de planification familiale. L'objectif principal de c'est étude, était trouver les déterminants d'usage contraceptif pour les femmes marié et l'implication politique en Tanzanie. La démographique de Tanzanie et l'étude sanitaire de 2004-2005 étaient utilisées. Les données étaient quantitativement analysé par régression logistique multinomiale et binaire. Les résultants montrent que, les déterminants d'usage contraceptif sont, la réprobation de mari sur l'usage de contraceptif, la connaissance des femmes, l'approbation de mari et femme sur le planning familial, la discussion des époux sur le planning familial, l'indice de fortune et religion. Aux termes de conformément à ces résultants, on recommande l'augmentation d'immatriculation des femmes en tout niveau de formation. C'est étude proposé que, c'est très important d'avoir la bonne politique d'accorder davantage d'autonomie à les femmes, mais il faut et très important d'exécute le programme efficacement.

Mots clé: Le planning familial; Les Déterminants; L’implication politique; Régression logistique multinomiale et Binaire

\footnotetext{
¥ Correspondence: Mackfallen G. Anasel, School of Public Administration and Management, Mzumbe University, P.O. Box 2 Mzumbe, Morogoro, Tanzania. Tel: 255-784705072. E-mail: mganasel@mzumbe.ac.tz
} 


\section{Introduction}

The population of any country is a crucial resource for the development. It is the resource of labour supply for production of goods and services as well as consumption of various products produced within and outside the country. Therefore, determination of the size of a population and its future growth is one of the most important parameters for economic development. Also the fact that population, growth increases demands for food, water, energy and other natural resources, it becomes imperative to the countries to attempt striking a balance between population growth and economic growth as well as the natural resources. Moreover, the growth and distribution of population structure also determines the demand for essential social services such as education, health, water, transportation, housing, as well as pension fund. To maintain sustainable economic development and improvement of well being of people as well as to maintain the environment, population growth should been kept at an appropriate level (Beegle, 1995).

Family planning 'allows individuals and couples to anticipate and attain their desired number of children and the spacing and timing of their births. It is achieved through use of contraceptive methods and the treatment of involuntary infertility. A woman's ability to space and limit her pregnancies has a direct impact on her health and well being as well as on the outcome of each pregnancy', (WHO, 1994).

The Tanzania demographic and Health survey show that knowledge of contraception is widespread in most parts of the country since $96 \%$ of women and $97 \%$ of men know at least one modern method. This is an increase from $91 \%$ of women and $92 \%$ of men in the 1999 Tanzania Reproductive and Child Health Survey (TRCHS). The most commonly known methods among men and women are the birth control pill, injectables, and male condoms. However, only one fourth of married women $(26 \%$, 2004-2005 Survey) are currently using family planning methods whereby $20 \%$ of them are using modern methods and $6 \%$ are using natural (traditional) methods. Injectable is the leading method, used by $8 \%$ of married women, and $6 \%$ of women use both pill and traditional methods
Furthermore, currently contraceptive use is higher among sexually active unmarried women than among married women $(41 \%$ and $26 \%$, respectively). The male condom is a favoured method among sexually active unmarried women (I5\%), (National Bureau of Statistics, 2005).

Increasing contraceptive use has been viewed as one of the mechanism to lower fertility level and eventually reduce population growth (Bongaarts, 1997; UN 1995). In addition, contraceptive use is one of factor that prevents maternal, infant and under-five mortality (Potts 1990; Yeakey \& Muntifering et al. 2009). However, it is not clear what factors are the most useful at achieving these goals. One approach is looking on the supply side as one of the causative of low utilization of family planning methods due to high-unmet need. On other hand, attitude, subjective norms and perceive behaviour towards family planning methods are believed to be factors that influence contraceptive use due to large gape between knowledge and contraceptive use. In addition, the expanding availability and choice of contraceptive methods, capacity building of health providers to deliver and support safe use of family planning services and strengthening service delivery systems may be one of determinants of contraceptive use, (NFPCIP 2010-2015). On top of that, background characteristics such as, education, wealth, parity, religion and place of residence as well as women status (attitudes, subjective norms, and perceived behavioural control) (Kelly et al, 2013; Msofe et al, 2009; Anna, 2006; Keele, et al, 2005), may be other factors that hinder the contraceptive use in Tanzania. The study was meant to look upon these factors and come out with findings and policy implication that will increase Contraceptive Prevalence Rate in Tanzania. Background characteristics and women status were analysed to find which factors had high influence on contraceptive use as it shown in figure I. The study aimed to answer two key questions: What are the background characteristics and women's status factors that contribute to contraceptive use? What are the determinants of contraceptive use: natural, temporary and permanent methods as compared to non-use of contraceptive methods? 


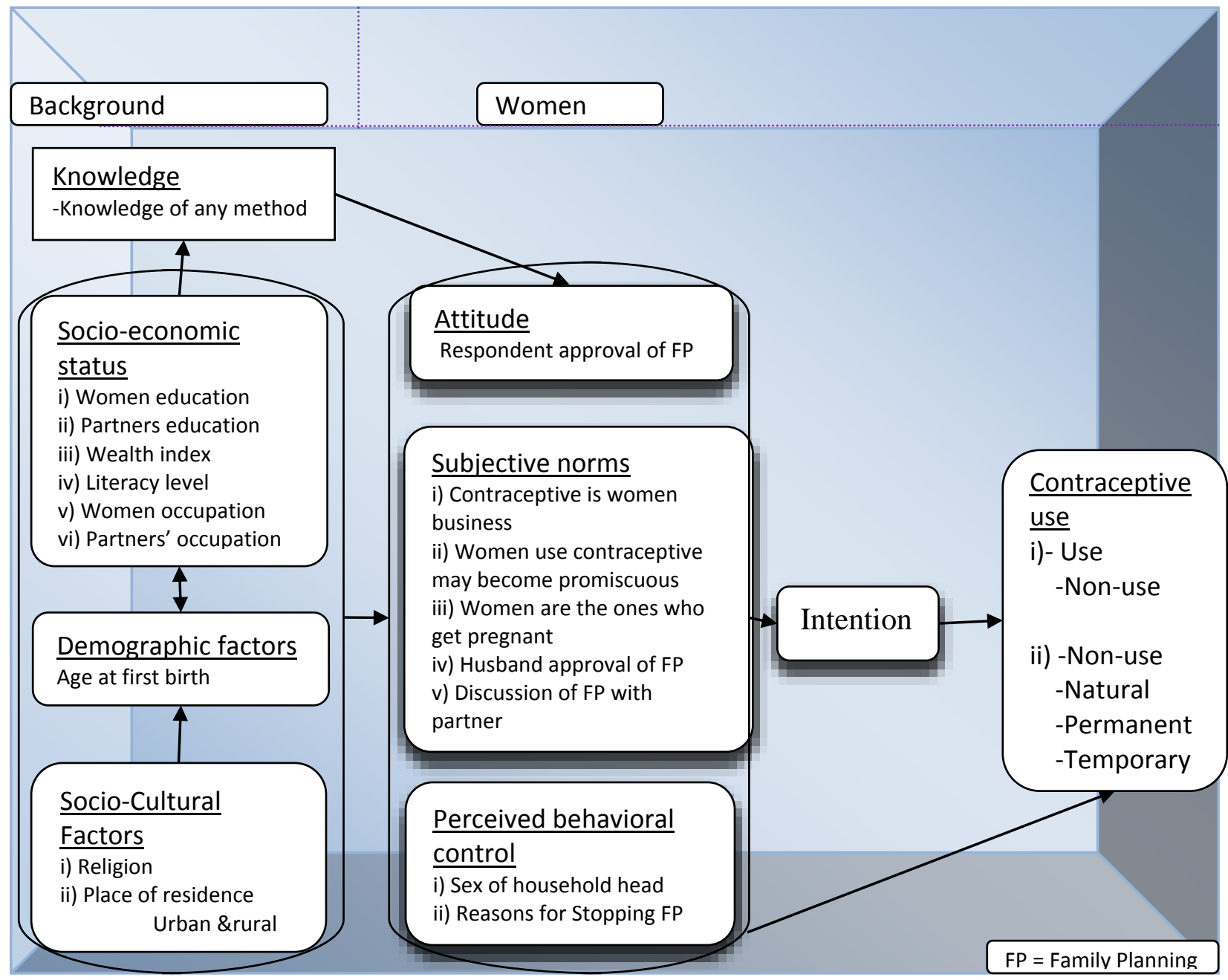

Figure I: Conceptual model adopted from Fishbein and Ajzen, (1975, 1980)

\section{Operationalized Conceptual Model}

The arrows on the conceptual model show the relation between one concept with another. Socioeconomic factors have an influence on contraceptive knowledge and knowledge has an influence on attitude towards contraceptive use. In addition, socio-cultural factors have the influence to demographic factors that interacts with socioeconomic status. Background characteristics have the influence on the women's status factors. Women status factors can determine the intension of women either to use or not to use family planning methods. In addition, the women status factors have direct influence to contraceptive use as well.

\section{Data and Methods}

The study used Tanzania Demographic and Health Survey dataset (2004-2005) that comprises of 2,635 individual males, 10,329 individual females and I,244 couples. The couple file, which was used, comprised IIII variables that included all demographic and health issues like fertility, family planning, child survival and child health. The important variable necessary for this analysis was recorded into new file from the couple file based on the concepts explained in conceptual model.

Examining contraceptive use and non-use falls under dichotomous outcome: hence it called upon the use of binary logistic regression, which is the most used model in analysing the probability of an event to occur. The new variable contraceptive use was computed from the former variable in couples' file "Current use by methods type" which had four values (No methods, folkloric methods, traditional methods and modern methods). It was grouped into two categories, use and non-use to become dichotomous dependent variable. The model is described in the following logit function below.

$\operatorname{Logit}(y)=\beta_{0}+\beta_{1} X_{1}+\beta_{2} X_{2} \ldots \beta_{p} X_{p}$

Estimate probability of use and non-use is given by;

$$
P(v=l)=\frac{\exp \left\{\beta_{0}+\beta_{1} X_{1}+\beta_{2} X_{2} \ldots \beta_{p} X_{p}\right\}}{1+\exp \left\{\beta_{0}+\beta_{1} X_{1}+\beta_{2} X_{2} \ldots \beta_{p} X_{p}\right\}}
$$

Where: $y$ is dichotomous dependent variable called logit defined as;

$y=(I=$ use of contraceptive; $0=$ nonuser of contraceptive) 


$$
\begin{aligned}
& \beta_{0}=\text { Intercept } \\
& \beta_{1,} \beta_{2,} \beta_{p}=\text { Logistic regression coefficient } \\
& \text { of } X_{1}, X_{2}, X_{p} \text { respectively } \\
& X_{1}, X_{2}, X_{p}=\text { Independent variables } \\
& \text { Exp }=\text { Exponential value }
\end{aligned}
$$

Lastly, the multinomial (polytomous) logistic regression was done to examine the relationship between dependent variable (non-user, temporary, permanent and natural methods) and set of independent variables. The binary logistic model was extended to multinomial since for each combination of values of independent variables, the count of dependent variable have more than two categories.

If the dependent variable has more than two values (non-user, temporary, permanent and natural methods), one value should be the baseline or reference category. For each the group, we calculated the odds ratio (probability) of being in that group as compared to being in baseline group. The baseline was comparison group and the coefficients were all zero. Non-user was selected as baseline category, which made its coefficient to be zero and generated the three sets of questions with non-zero coefficients. The multinomial logistic regression model is written as:

$\log \left(\frac{P\left(\text { category }_{i}\right)}{P\left(\text { category }_{j}\right)}\right)=\beta_{i 0}+\beta_{i 1} X_{1}+\beta_{i 2} X_{2} \ldots \beta_{i p} X_{p}$

Where: $\log \left(\frac{P\left(\text { category }_{i}\right)}{P\left(\text { category }_{j}\right)}\right)$

$=$ Logit, Natural log of the odds that the event occurs

$j=$ baseline category of $i^{\text {th }}$ categories;

$\beta_{i 0}=$ Intercept;

$\beta_{i 1}, \beta_{i 2}, \beta_{i_{p}}=$ Logistics regression coefficients and

$X_{1}, X_{2}, X_{p}=$ Independent variables.

\section{Result}

The analysis starts with descriptive statistics which involves analysis of frequency and cross-tabulation to explore the relationship between the categorical dependent variable and categorical independent variables. The first part examines the relation between dependent variable (use and non-use of contraceptive) and independent variables (Background characteristics and women's status). Second part involves analysing the relation between non-use, natural, permanent and temporary methods (dependent variable) and independent variables.

Cross-tabulation with frequencies and percentage of each variable was performed. Moreover, the person Chi-Square statistics was used to analyse whether there was a significance difference between the expected frequencies and observed frequencies in each category in use and non-use of contraceptive.

\section{Background characteristics}

It was noted that all background variables (women education, partner education level, wealth index, literacy level, women occupation, partner occupation, age at first use, religion, and place of residence) were significantly different among users and non-users of the contraceptive methods $(p<0.05)$. Results showed that knowledge on modern contraceptive methods for non-user was very high $(85.7 \%$ for traditional and $75 \%$ for modern methods) yet they were not using it. User shows positive relation between knowledge and contraceptive use. $25.1 \%$ of respondents who know modern methods are users whereby the methods seemed to be used by $20 \%$ of them, also $14.3 \%$ of the respondents who know traditional methods are users in which the methods are used by $6 \%$ of them

Furthermore, the percentages of contraceptive use increase as education level increase for both women and men starting from $10.9 \%$ to $52.9 \%$ and $11.6 \%$ to $50.0 \%$ respectively. On other hand, the percentages of non-use decrease as level of education increases for both women and men starting from $89.2 \%$ to $47.1 \%$ and $88.4 \%$ to $50.0 \%$ respectively. It is also observed that, contraceptive use increases as wealth index increases from the poorest to the richest starting from $16.3 \%$ to $41.6 \%$ as compared to non-user where percentages decrease from $83.7 \%$ to $58.4 \%$. Findings show that women who are able to read all sentences have high percentage of contraceptive use amount to $28.0 \%$. In addition, women and men occupations have the influence on contraceptive use. Clerical, Professor, Technician, and Manager as well as household and domestics have more than $50 \%$ chances in contraceptive use for women while for men clerical is only the category which has percentage more than $50 \%$ that is $83.3 \%$.

Demographic factor reveals that, women who give the first birth at age between 10-19 years have 
low percentage of contraceptives use as compared to women at age group 25-29 years who have high percentage of contraceptive use. Group that has first birth at age 10-14 years has $90.2 \%$ of non-use of contraceptive contrary to first birth at 25-29 years, which have $41.5 \%$ of contraceptive use.

Furthermore, socio-cultural factors were analysed involving two variables, religion, and place of residence. The following results were observed in religion variable, Protestants are more likely to use family planning $32.4 \%$ followed by Catholics $27.0 \%$ and lastly were Muslims $23.0 \%$. Urban area had high percentage in contraceptive use as compared to rural area with ratings at $39.0 \%$ and $21.3 \%$ respectively.

\section{Women's status}

The relationship between contraceptive use and women's status examines attitude, subjective norms and perceived behavioural control among married women towards contraceptive use. All variables are significantly different between user and non-user of contraceptives $(P<0.05)$, except for the statement that, sterilization of women becomes promiscuous, and the sex of head of household ( $p>0.05)$.

Attitude was measured by assessing the respondent's approval of family planning. Results showed that $26.9 \%$ of the users approve and use family planning methods while $73.1 \%$ approve yet they are not using it. $90.6 \%$ among non-users disapprove and $9.4 \%$ of users disapprove however they are using. Another, concept analysed was a subjective norms, which comprised the following variables, husband approves the family planning methods, and respondent discusses family planning with partner. In addition, there were statements that men were asked concerning contraceptive use: contraceptive use is women's business and a man should not worry about it; women who use contraceptive may become promiscuous; and since a woman is the one who gets pregnant then she should be the one to use contraceptive. Those women whose husbands approve the use of family planning have a high percentage of contraceptive use $(36.8 \%)$ as compared to those who did not get approval from their husbands (8.8\%). Moreover, women who frequently discuss family planning with their partners are more likely to use family planning $(41.0 \%)$ as compared to those who discuss once $(27.2 \%)$ or who never discuss $(4.3 \%)$. There was no direct report from men which gives a clear picture on those who agree or disagree with statement since the percentages were more less the same.
The last concept analysed was perceived behavioural control that had two variables, sex of household head, and reasons for stopping family planning methods. Reason for last discontinuation was analysed and the following were the key findings: $66.7 \%$ of non-user revealed that their stopping was due to the side effects encountered, 63.3\% wanted to become pregnant, $63.0 \%$ had problems with access and availability of contraceptive commodities and $56.2 \%$ stopped due to their husbands' disapproval of the contraceptive use. Sex of household head did not show any significant relation with contraceptive use and the percentage were $24 \%$ for males and $22.9 \%$ for females.

The cross tabulation results between the categorical dependent variable (non-use, natural, temporary, and permanent methods) and background independent variables results are more less the same as the result in first descriptive analysis with minor differences. All variables have $p<0.05$ which show there significant difference between the dependent variable and independent variables. The variables in women's status have $p<0.05$ except the statement that women is the one who can get pregnant and sex of household head which they have $p>0.05$. These variables were removed from further analysis in multinomial regression model.

What are the background characteristics and women's status factors that contribute to contraceptive use?

To answer this question a binary logistic regression analysis was done to find out the probability of use and non-use of family planning based on the set of background characteristics and women's status factors (independent variables).

Separately, analysis was done for each concept i.e socio-economics status, demographic factors and socio-cultural factors in background characteristic as well as attitude, subjective norms, and perceived behavioural control for women's status. Only those variables that had shown to be significantly different between users and non-users in the descriptive analysis were included in the logistic model. For that reason, sex of household head and the statement that sterilized women become promiscuous were not included.

First step, concepts in background characteristics were entered in to the model separately and those with significance level higher than $0.05(p>0.05)$ were removed from the model. The remaining variables were rerun so as to examine the model fit. The variables that had high $p$ values greater than 
0.05 were again removed from the model while those with $p<0.05$ were retained. Secondly, the women's status variables were entered to the model and the variables that had the $p$ values greater than 0.05 were removed from the model. The remaining variables were rerun and variables with $p<0.05$ were selected. Lastly, the variables that were selected from background characteristics concepts and that from women's status were entered into the regression model to produce the final logistic regression model.

Table I: Variable in equation final model

\begin{tabular}{|c|c|c|c|c|c|c|}
\hline & & $\mathrm{B}$ & Wald & $\mathrm{df}$ & Sig & $\operatorname{Exp}(B)$ \\
\hline \multirow[t]{4}{*}{ Women education } & No education & Reference & $12.60 \mid$ & 3 & 0.006 & \\
\hline & Primary & 0.397 & 3.170 & $\mathrm{I}$ & 0.075 & $\mathrm{I} .487$ \\
\hline & Secondary & 1.052 & 8.177 & I & 0.004 & 2.864 \\
\hline & Higher & 1.906 & 7.577 & I & 0.006 & 6.727 \\
\hline \multirow[t]{3}{*}{ Husband approval of Family Planning } & Disapproves & Reference & 32.449 & 2 & 0.0001 & \\
\hline & Approves & 1.214 & 26.063 & I & 0.0001 & 3.367 \\
\hline & Don't know & -0.787 & 1.465 & I & 0.226 & 0.455 \\
\hline \multirow[t]{3}{*}{ Discussion of FP with partner } & Never & Reference & 37.069 & 2 & 0.0001 & \\
\hline & Once or twice & $|.42|$ & 21.215 & I & 0.0001 & 4. 142 \\
\hline & More often & $\mathrm{I} .829$ & 36.238 & 1 & 0.0001 & 6.229 \\
\hline Constant & & -4.464 & 48.990 & $\mathrm{I}$ & 0.0001 & 0.012 \\
\hline
\end{tabular}

Result of Final model of logistic Regression

Variables that showed significant in each concept were included in the model and those with $p>0.05$ were removed from model. Moreover, the variables with highest $p$ values were removed first and the model fit and significance were rechecked again. This procedure was done until all variables in the model were significant.

The final model is shown in Table I where three variables have $p$ values $<0.05$. Variables in the final model are women education, husband's approval of family planning and discussion of family planning with partner.

Table I shows that the odds of contraceptive use increased with borderline significance by 1.487 for women with primary education as compared to non-educated. On the other hand, the odds of contraceptive use increased by factor of 2.864 for women with secondary education as compared to the non-educated. Lastly, the odds of contraceptive use are increasing by factors of 6.727 for respondent with high education as compared with the noneducated.

Other variables that show significances in the final model are husband approval of family planning, and discussion of family planning with partner. Odds of contraceptive use increase by factors of 3.367 if husband approves for family planning methods as compared to husband disapproves for contraceptive use. The odds of contraceptive use increase by factor of 4.142 for couples that have discussion on contraceptive use once or twice as compared to those who didn't discuss on family planning methods. Likewise, the odds of contraceptive use increase by factor of 6.229 if the couple have often discussion on family planning as compared with those who do not have discussion on family planning methods. Thus from the result we found that women's education, husband approval of FP and discussion of FP by partner are significant.

What are the determinants of contraceptive use: natural, temporary and permanent methods as compared to non-use of contraceptive methods?

In the third part of analysis the three categories of contraceptive use were analysed against the nonuser. This involves extension of the categorical dependent outcome from two categories to four categories, natural, temporary permanent and nonuser. 
Table 2: Parameter estimates in multinomial regression model

\begin{tabular}{|c|c|c|c|c|c|c|c|}
\hline Contraceptive use $^{\mathrm{a}}$ & & Variables & $\mathrm{B}$ & Wald & $\mathrm{df}$ & Sig. & $\operatorname{Exp}(B)$ \\
\hline Natural methods & & Intercept & -4.775 & 33.619 & $\mathrm{I}$ & 0.0001 & \\
\hline \multirow[t]{5}{*}{ Wealth Index } & & Poorest & -0.969 & 4.088 & i & 0.043 & 0.379 \\
\hline & & Poorer & -0.499 & 1.517 & i & 0.218 & 0.607 \\
\hline & & Middle & -1.338 & 7.743 & i & 0.005 & 0.262 \\
\hline & & Richer & -0.874 & 4.198 & i & 0.04 & 0.417 \\
\hline & Reference & Richest & $0^{\mathrm{b}}$ & & 0 & & \\
\hline \multirow[t]{4}{*}{ Religion } & & None & 1.352 & 6.065 & 1 & 0.014 & 3.863 \\
\hline & & Protestant & 0.954 & 7.276 & I & 0.007 & 2.595 \\
\hline & & Catholic & 0.436 & 1.21 & i & 0.271 & 1.547 \\
\hline & Reference & Moslem & $0^{\mathrm{b}}$ & & 0 & & \\
\hline \multirow[t]{3}{*}{ Women approval of Family Planning } & & Don't know & -17.307 & 0.000 & 1 & 0.998 & 0.000 \\
\hline & & Approves & 0.306 & 0.204 & i & 0.651 & 1.358 \\
\hline & Reference & Disapproves & $0^{\mathrm{b}}$ & & 0 & & \\
\hline \multirow[t]{3}{*}{ Husband approve of Family Planning } & & Don't know & -17.372 & 0.000 & 1 & 0.997 & 0.000 \\
\hline & & Approves & 0.686 & 2.356 & I & 0.125 & 1.985 \\
\hline & Reference & Disapproves & $0^{\mathrm{b}}$ & & 0 & . & \\
\hline \multirow[t]{3}{*}{ Discussion of FP with partner } & & More often & 2.022 & 9.969 & 1 & 0.002 & 7.553 \\
\hline & & Once or twice & 1.565 & 5.911 & i & 0.015 & 4.782 \\
\hline & Reference & Never & $0^{\mathrm{b}}$ & . & 0 & . & . \\
\hline Temporary methods & & Intercept & -4.639 & 46.842 & 1 & 0.0001 & \\
\hline \multirow[t]{5}{*}{ Wealth Index } & & Poorest & -0.654 & 5.628 & i & 0.018 & 0.520 \\
\hline & & Poorer & -0.576 & 4.92 & 1 & 0.027 & 0.562 \\
\hline & & Middle & -0.736 & 8.301 & 1 & 0.004 & 0.479 \\
\hline & & Richer & $-0.35 I$ & 2.247 & 1 & 0.134 & 0.704 \\
\hline & Reference & Richest & $0^{\mathrm{b}}$ & 然 & 0 & & \\
\hline \multirow[t]{4}{*}{ Religion } & & None & -0.449 & 0.915 & I & 0.339 & 0.638 \\
\hline & & Protestant & 0.261 & 1.722 & 1 & 0.189 & 1.298 \\
\hline & & Catholic & 0.064 & 0.096 & i & 0.757 & 1.066 \\
\hline & Reference & Moslem & $0^{\mathrm{b}}$ & & 0 & & \\
\hline \multirow[t]{3}{*}{ Women approve of Family Planning } & & Don't know & -16.426 & 0.000 & 1 & 0.997 & 0.000 \\
\hline & & Approves & 1.538 & 6.272 & 1 & 0.012 & 4.657 \\
\hline & Reference & Disapproves & $0^{\mathrm{b}}$ & & 0 & & \\
\hline \multirow[t]{3}{*}{ Husband approve of Family Planning } & & Don't know & -0.211 & 0.097 & 1 & 0.756 & 0.810 \\
\hline & & Approves & 1.114 & 15.440 & i & 0.0001 & 3.045 \\
\hline & Reference & Disapproves & $0^{\mathrm{b}}$ & & 0 & & \\
\hline \multirow[t]{3}{*}{ Discussion of FP with partners } & & More often & 1.834 & 27.74 & $\mathrm{I}$ & 0.0001 & 6.259 \\
\hline & & Once or twice & 1.468 & 17.299 & I & 0.0001 & 4.339 \\
\hline & Reference & Never & $0^{\mathrm{b}}$ & & 0 & & \\
\hline Permanent methods & & Intercept & $-4.97 \mid$ & 17.352 & I & 0.0001 & \\
\hline \multirow[t]{5}{*}{ Wealth Index } & & Poorest & -0.856 & 1.035 & 1 & 0.309 & 0.425 \\
\hline & & Poorer & -0.670 & 0.834 & 1 & 0.361 & 0.512 \\
\hline & & Middle & -0.160 & 0.068 & i & 0.794 & 0.852 \\
\hline & & Richer & -0.550 & 0.681 & 1 & 0.409 & 0.577 \\
\hline & Reference & Richest & $0^{\mathrm{b}}$ & & 0 & & \\
\hline \multirow[t]{4}{*}{ Religion } & & None & -17.726 & 0.000 & 1 & 0.998 & 0.000 \\
\hline & & Protestants & 0.807 & 2.359 & I & 0.125 & 2.24 \\
\hline & & Catholics & 0.212 & 0.121 & 1 & 0.728 & 1.236 \\
\hline & Reference & Muslims & $0^{\mathrm{b}}$ & . & 0 & . & \\
\hline \multirow[t]{3}{*}{ Women approve of Family Planning } & & Don't know & -16.829 & & 1 & & 0.000 \\
\hline & & Approves & 0.321 & 0.076 & I & 0.782 & 1.379 \\
\hline & Reference & Disapproves & $0^{\mathrm{b}}$ & & 0 & & \\
\hline \multirow[t]{3}{*}{ Husband approve of FP } & & Don't know & -17.587 & 0.000 & 1 & 0.998 & 0.000 \\
\hline & & Approves & 1.233 & 2.103 & 1 & 0.147 & 3.433 \\
\hline & Reference & Disapproves & $0^{\mathrm{b}}$ & & 0 & . & \\
\hline \multirow[t]{3}{*}{ Discussion of FP with partner } & & More often & 0.558 & 0.663 & 1 & 0.415 & 1.747 \\
\hline & & Once or twice & 0.058 & 0.006 & 1 & 0.937 & 1.06 \\
\hline & Reference & Never & $0^{\mathrm{b}}$ & . & 0 & . & \\
\hline
\end{tabular}

a. The reference category is: Non-use.

b. This parameter is set to zero because is redundant

Final model: Multinomial logistic regression

Analysis was done by including the variable with $\mathrm{p}<0.05$ from the cross tabulation in the model. Secondly, the multinomial regression was done for each concept and the variables that had $p<0.05$ were identified for the final model. Thirdly, final multinomial logistic regression model was run and a variable that was not significant in all categories of dependent variable, with highest $p$ value was removed first. The process of removing variables from the model was done one after another until all remaining variable became significant at least with one category in dependent variable. This is well demonstrated in Table 2

The findings of final multinomial model in table 2 revealed that, the odds ratio of using natural 
methods relative to not using any method is 0.379 for the poor people as compared to the rich, meaning that poor people are more likely to use natural methods than richer people. On other hand, the odds of using natural methods instead of not using any methods decrease non-significantly by a factor of 0.607 by being poorer rather than the richest. Then after, the odds decrease significantly with wealth index 0.262 for middle and 0.417 for richer. Moreover, the odds of natural contraceptive use are significant at increasing by factor of 3.863 for non-religious and 2.595 for Protestants, and increase non-significantly by factor of 1.547 for Catholics as compared to the Muslim (reference). In addition, women and husband approval of family planning are increasing at non-significant odds ratios when compared with other independent variables in natural contraceptive use. Likewise, odds for use natural contraceptive methods as a substitute of being non-user is increasing significantly by factor of 7.553, 4.782 for those have discussed once or twice about family planning with partner respectively as compared to those never discuss with their partners about family planning.

Furthermore, all variables and most of its categories show significant odds of temporary contraceptive use in its place of non-using except for religion which is insignificant. The odds of temporary contraceptive use relatively to non-use are decreasing significantly by factor of $0.520,0.562$, and 0.479 for the poorest, poorer, and middle respectively as compared to richest. While the odds of temporary contraceptive use in its place of nonuser is decreasing non-significantly by factor of 0.704 for the richer as compared to richest, the odds of use temporary contraceptive methods rather than being non-user is increasing significantly by factor of 4.657 for women who approve contraceptive use, and 3.045 for husbands who approve contraceptive use as compared to those who disapprove. Lastly, the odds of using temporary methods for women who discuss on family planning with their partners more often and once or twice are increasing by factors of 6.259 and 4.339 respectively as compared to those who never discuss.

Lastly, the odds of permanent contraceptive use as substitute of being non-user for wealth index (poorest, poorer, middle, and richer) is decreasing non-significantly as compared to the richest. The remaining variables; religion, women approval of family planning, husband approval of family planning, and discussions of family planning with partner are increasing non-significantly as compared to highest category in each.

\section{Discussion}

People in countries that maintain a balanced population growth have qualitatively comfortable life as opposed to people living in an over-populated country. Even if the country is richly endowed with natural resources, there may be; poverty, hunger, unemployment, disease, and lawlessness; as these are by products of overpopulation (Beegle, 1995). In order to stabilize population growth, it is necessary to balance birth which is one of the factors that regulate population growth. To realize this cost, effective intervention is needed to increase the Contraceptive Prevalence Rates.

Between background characteristics and women status factors, three variables are significant in binary and five variables in multinomial logistic regression. In binary logistic regression, women education, husband approval of family planning, and discussions of family planning with partner were significant. For the multinomial regression; wealth index, religion, women (respondent) approval of family planning, husband approval of family planning, and discussion of family planning with partners were significant. The odds of contraceptive use increased significantly for women with secondary education and high education. It starts non-significantly with low factor for primary education and increase significantly as level of education increases with highest factor of 6.727 for higher education as compared to noneducated. Husband approval of family planning is another variable that has odds related to contraceptive use. Lastly, couples that have often discussion about family planning have highest odds of contraceptive use followed with those have had once or twice discussion as compared with those does not totally discuss.

Men being the decision makers in the households prevent women from using family planning methods without consent from the man (Schuter et al, 2009). In addition, study conducted by Oyedokun, (2007) at Osun State Nigeria reveals that, women who discussed with their partners about contraceptive use and those women who approved use of family planning methods were found to be less likely to ever use any modern contraceptive methods. This implies that women's approving a family planning method does not necessarily mean that they will ever use any of the approved methods. 'The result indicates that men are the primary decision-makers on issues relating to fertility and fertility control. Previous studies show that male dominance in 
decision-making is one of key factor in contraceptive use. A study conducted by Almaz (1993) in Ethiopia found that couples whose husbands participated in home-visit talks were more likely to initiate contraceptive use and adopting modern contraception one year after the visit than couples in which only the wife participated. Moreover, Zimbabwe National Family Planning Council (ZNFPC) in 1988/89 conducted a first national education project targeting men aiming to increase men's contraceptive knowledge and eventually increase contraceptives use. Second, campaign was launched in 1993 encouraged male involvement in family planning and use of long-term methods to limit family size. The analysis of first study found that men exposed to the campaign were I.4 times likely to use modern family planning methods as compared to non-exposed men. In addition, the evaluation of the second study revealed that people exposed to three or more campaign components (radio, television, posters, newspapers, motivational talks, family festivals, live dramas, and musical shows) were 1.6 times as likely to use a modern contraceptives methods compared to others (Kim, et al., 1996). There is a need of involving males in family planning programs as an actor that will create understanding for them about importance and how to use the available methods. Also it may reduce the misconception that men have towards family planning methods that cause the most of non-users and those who discontinues from using family planning for the fear of its side effects.

In addition, multinomial logistic regression in this study shows that the odds of use natural family planning methods rather than being non-user is decreasing significantly in all categories of wealth index except for poorer as compared to richest. The coefficients (B) in regression explain the relationship between logit (dependent variable) and independent variable, (Norusis, 2008). Therefore, negative coefficients in wealth index indicate that the poorest, middle and richer are less likely than richest in using natural methods rather than being non-user. Furthermore, non-religious and Protestants have odds ratio (positive coefficients) which increases significantly. This situation implies that non-religious and Protestants are likely to use natural methods rather than being non-user as compared to Muslims. Roman Catholics were expected to be one of the main users of natural family planning methods as it is advocated by most of their church leaders to use natural methods or abstinence (Anna et al, 2006). Surprisingly, the study finding show that non- religious women and Protestants are likely to use natural family planning. Moreover, women approval of family planning and husband approval of contraceptive use have positive coefficient values, indicating that compared to those who disapprove women and men (husbands) who approve are more likely to use natural family planning methods rather than being non-users.

Furthermore, the findings show that temporary methods have significant relationship with wealth index, women's approval of family planning, husband approval of family planning, and discussion of family planning with partner. A book titled Tanzania Social Sector Review by Word bank (1999), identifies women age, education level, religion affiliation and wealth index as strongly associated with modern contraceptive use (Temporary and permanent methods). Moreover, education level and income are one of the variables that are associated with modern contraceptive use among married Sudanese women, (lbnouf et al, 2007).

This study creates the need for women empowerment through income-generation activities as well as improving standards of living of whole community. Advocating women education and increase enrolment in both primary and secondary schools and eventually at University level might help in solving the income (wealth index) problem and would increase awareness on family planning methods and eventually increase contraceptive use.

Although knowledge and perceived behaviour control are thought to determine contraceptive use, the data used in this study limited our examination to hearing of any family planning methods, and main reasons for stopping family planning methods. The 2004-2005 TDHS was only testing the respondent recalls hearing on family planning methods. The recall was either spontaneous (without the interviewer mentioning the method) or prompted (interviewer mentioning the method). So, the results provided in TDHS include both spontaneous and prompted answers. These questions do not capture the complexity of knowledge on family planning methods by respondent knowing how to use it, its effectiveness and associated side effects with family planning. The questions may be improved by asking the respondent, the source of the information about family planning methods, what are the knowledge they have concerning family planning methods, and if he/she has an access of visiting a family planning centre in his/her areas.

Furthermore, perceived behaviour control also lacks information that explains it in broader 
perspective. The questions do not capture any insights on availability of contraceptives at health facilities, distance from household to centre that provide family planning services, ownership of health facilities (private/mission or government) close to respondents and also behaviour of health workers towards family planning clients. Besides the observed shortfalls, the study adds knowledge on the existing literature on family planning especially in the Sub Saharan countries. The use of two methods (Binary and multinomial regression) in this paper, which is rarely been used in many studies, has added the value to the study findings. From the findings we see some of similarities in these two model and differences in determinates of contraceptive use.

\section{Policy implication}

Firstly, the study findings show that educated women have high chance of using family planning methods. Therefore we suggest promotion on female education by creating good environment for increasing women enrolment in primary, secondary and even at university level, and having nice plan and policy and a clear strategy for implementation are very crucial for successful use of family planning methods.

Second, religious belief against family planning must be countered through training religious leaders on benefits available in birth control for individual and nation as whole. Also the family planning programs should include and orientation workshops for religious leaders to have positive perception on family planning methods.

Third, one of the reasons for non-users not to use family planning and discontinuation is the fear of its side effects. Therefore, Ministry of Health and Social Welfare together with other stakeholders as well as non-profit organizations (NGOs) should address the issue through adequate and reliable information, timely follow-up of users and improving the knowledge and technical competence of service providers.

Fourth, some of clients have discontinued from family planning due unavailability problem, so there is the need to increase supply of family planning methods in all places timely and optimally through involving voluntary, religious and private health facilities in provision of family planning services to back-up the government efforts.

Lastly, results indicate strong relation between contraceptive use and discussion among the partners in the couples about family planning methods. The Ministry of Health and Social Welfare and other stakeholders should focus on male involvement as an actor by improving their awareness on the benefit associated with various family planning methods. Thus, all family planning programs should target males directly on discussion and plan about contraceptive use with their partners. This can be done through the mass media communication advocating male involvement in family planning and the importance of male attending at Maternal and Child Health Clinics ( $\mathrm{MCHC}$ ) for family planning education and services.

\section{Author's contribution}

All named authors have contributed sufficiently to the work submitted and that the content of the manuscript has never been previously published in other Journals.

\section{References:}

Almaz Terefe and Charles P. Larson, (1993) 'Modern Contraception Use in Ethiopia: Does Involving Husbands Make a Difference?' American Journal of Public Health, 83(I I), I 567-I 576.

Anna T. K \& Nassoro R. (2006), 'Utilization of modern family planning methods among women of reproductive age in rural setting: the case study of Shinyanga rural district, Tanzania, East Africa Journal of Public Health 3(2), 26-30.

Beegle, K. (1995), 'The quality and Availability of Family Planning Servises and Contraceptive use in Tanzania', LSMS Working paper number I/4, The World Bank: Washington, D.C.

Bongaarts, J. (1997). Trends in unwanted childbearing in the developing world. Studies in Family Planning, 28 (3): 267-27.

Ibnouf A.H, H. W. Van den Born \& Maarse J. A. M (2007), 'Utilization of family planning services by married Sudanese women of reproductive age', Eastern Mediterranean Health Journal, WHO 13(6).

Keele, J. J., Forste, R., \& Flake, D. F. (2005). Hearing native voices: Contraceptive use in Matemwe village, east Africa. African Journal of Reproductive Health, 9(I), 32-4I.

Kelly L. L'Engle, Heather L. Vahdat, Elizabeth Ndakidemi, Christine Lasway, Trinity Zan, (2013). Evaluating feasibility, reach and potential impact of a text message family planning information service in Tanzania: Contraception, 87(2), 25I-256.

Kim, Y.M., C. Marangwanda, and A. Kols, (1996), Involving Men in Family Planning: The Zimbabwe Male Motivation and Family Planning Method Expansion Project, 1993-1994, Baltimore: Johns Hopkins School of Public Health, Center for 
Communication Programs. National Bureau of Statistics (NBS) and ORC Macro (2005), Tanzania Demographic and Health Survey 2004-2005, Dar es Salaam Tanzania: National Bureau of Statistics and ORC Macro.

Norusi, M. J. (2008), SPSS Statistics 17.0 Advanced Statistical Procedures Companion: Prentice Hall Inc: Upper Saddle River.

Norusi, M. J. (2008), SPSS Statistics 17.0 Guide to data analysis: Prentice Hall Inc: Upper Saddle River.

Norusi, M. J. (2008), SPSS Statistics 17.0 Statistical Procedure companion: Prentice Hall Inc: Upper Saddle River.

Potts, M. (1990). "Family planning is crucial to child survival: Network II (4): 2.

Msofe, Grace E.P Kiondo, Elizabeth. (2009). Accessibility and use of family planning information (FPI) by rural people in Kilombero District. Africa Journal of Library, Achives and Information Science 19(2), I I7-I 27.

Oyedokun A.O (2007), 'Determinant of contraceptive Usage; Lesson from women in Osun State Nigeria', Humanities \& Social Science, I(2), I-I4.
Schuler, S., E. Rottach, and M Peninah (2009), 'Gender norms and family planning decisionmaking in Tanzania: A qualitative study. Washington, DC: C-Change.

United Nations (1995), 'Population and Development' Programme of Action adopted at the International Conference on Population and Development, Cairo, 5-13 September 1994: New York.

United Republic of Tanzania, Ministry of Health and Social Welfare, (2010), National Family Planning Costed Implementation Program 2010-2015, Dar es Salaam Tanzania: Ministry of Health and Social Welfare.

World Bank, (1999), Tanzania Social Sector review, World Bank, Washington D.C USA.

Yeakey, M. P., C. J. Muntifering, et al. (2009). "How contraceptive use affects birth intervals: results of a literature review: Studies Family Planning 40(3): 205-2।4. 